\title{
Echographic measurements of the retrobulbar optic nerve in normal and glaucomatous eyes
}

\author{
S Beatty, P A Good, J McLaughlin, E C O’Neill
}

\begin{abstract}
Aim-A study was designed to investigate whether measurements of the optic nerve diameter (OND) and cross sectional area (ONCSA), as measured by B-scan ultrasonography, are altered in glaucoma. The reproducibility and test-retest variability of echographic estimates of retrobulbar optic nerve dimensions was also tested.

Methods-One eye of 49 glaucoma patients and 90 control subjects underwent five repeated echographic measurements of the maximal interpial diameter and cross sectional area of the orbital optic nerve on two separate occasions. All measurements were taken by one experienced ultrasonographer.
\end{abstract}

Results-Mean optic nerve diameter (SD) for the control group was $2.86(0.46) \mathrm{mm}$, and was independent of height (multiple regression analysis: $p=0.21$ ), axial length $(p=0.74)$, spherical equivalent $(p=0.97)$ sex (ANOVA: $p=0.36$ ), or race $(p=0.14)$, but was inversely related to age $(p=0.01)$. Reproducibility of OND readings in control subjects was $0.149 \mathrm{~mm}$ (coefficient of repeatability). Test-retest variability of interpial diameter was $-0.02(0.29) \mathrm{mm}$. Mean interpial diameter of the optic nerve was significantly smaller among glaucomatous eyes $(2.58(0.501) \mathrm{mm})$ than controls (Mann-Whitney U test: $p<$ 0.0001). Glaucomatous optic nerves also had a significantly smaller cross sectional area $\left(6.68(2.58) \mathrm{mm}^{2}\right)$ than those of healthy volunteers $\left(8.25(1.67) \mathrm{mm}^{2}\right)(p=$ 0.004).

Conclusion-Echographic measurements of the orbital optic nerve are highly reproducible and not subject to clinically meaningful test-retest variability. Optic nerve interpial diameter and cross sectional area are reduced in glaucomatous eyes, reflecting nerve fibre loss. This technique may be useful in distinguishing between normal and glaucomatous eyes where optic disc morphometry is inconclusive or impossible as a result of opaque media. (Br f Ophthalmol 1998;82:43-47)

Visual impairment related to glaucomatous damage can only be prevented if the disease process is identified and treated early in its course. Perimetry, morphometric evaluation of the optic nerve head, and the results of tonometry all contribute to the final diagnosis of glaucoma. However, several factors may restrict the role of these functional and morphological variables in the assessment of the glaucoma suspect. These include opaque media, optic disc anomalies, and the physical and mental limitations of the patient. Furthermore, the possibility of ocular hypertension and low tension glaucoma confounds the usefulness of intraocular pressure measurements. Therefore, an objective method of assessing the glaucoma suspect, independent of IOP and optic nerve head morphometry, would be a useful addition to the current array of investigations.

To date, however, the diagnostic potential of orbital optic nerve measurements in glaucoma has been restricted by the poor resolving power of B-scan ultrasound in the retrobulbar region. ${ }^{1}$ We used a new generation $\mathrm{B}$ scanner to measure orbital optic nerve dimensions in eyes with glaucoma and ocular hypertension, and compared the results with those of control subjects. We also calculated the reproducibility and test-retest variability of our readings, and investigated the effect of other ocular and nonocular variables on optic nerve measurements.

\section{Patients and methods}

The inclusion criteria for control subjects in this study were: a visual acuity of $6 / 9$ or better in either eye; a myopic refractive error not exceeding -8.00 dioptres $^{2}$; and no demonstrable intraocular pathology. Most control subjects were patients attending the accident and emergency department of the Birmingham and Midland Eye Centre (BMEC) with external eye disease, and some were enrolled from the clinic staff.

Forty nine glaucoma subjects attending the visual function department of the BMEC for field analysis were recruited. Of these, all suffered from primary open angle glaucoma. In each case, this diagnosis was made in the presence of raised intraocular pressure $(>21 \mathrm{~mm}$ $\mathrm{Hg}$ ), arcuate field defects, and glaucomatous optic disc changes. Ocular hypertension (OHT) was diagnosed if intraocular pressure was $\geqslant 24 \mathrm{~mm} \mathrm{Hg}$ on at least two separate occasions in an eye with normal optic disc morphometry and no detectable field defect on standard automated perimetry. Using these criteria, 17 ocular hypertensive eyes were included in this study. All eyes with glaucoma or OHT that were only included in this study had a visual acuity of $6 / 9$ or better, and a myopic refractive error of less than -8.00 dioptres.

Retrobulbar optic nerve diameter was measured using standardised, high resolution B-scan and A-scan echography (Biovision B-Scan, Chiron Vision, UK). The ultrasound probe is focused at $27 \mathrm{~mm}$ from the concave
Accepted for publication 18 September 1997 


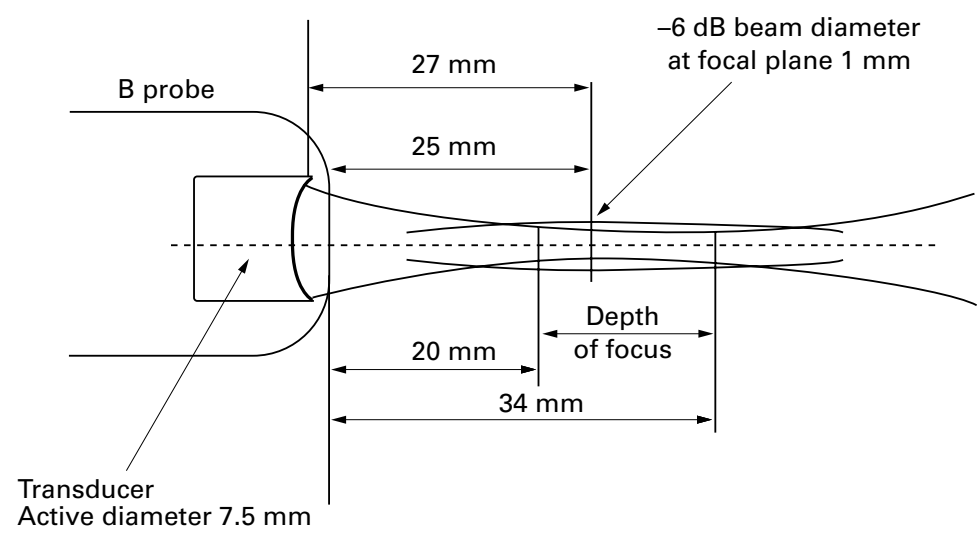

Figure 1 Diagrammatic representation of the B-scan probe. The radius of concavity of the transducer is approximately equal to its focal distance $(27 \mathrm{~mm})$. As the transducer is $2 \mathrm{~mm}$ inside the probe, this ensures an external focus of $25 \mathrm{~mm}$.

transducer (that is, $25 \mathrm{~mm}$ inside the eye), resulting in greater resolution of orbital structures than its predecessors. This probe has a lateral resolution of $<0.8 \mathrm{~mm}$ within the depth of focus $(20-34 \mathrm{~mm})$ and achieves lateral and axial resolutions at the focal plane of $0.3 \mathrm{~mm}$ and $0.12 \mathrm{~mm}$ respectively (Fig 1). The technique we used is similar to that described in the literature. ${ }^{34}$ Briefly, the patient was asked to move his/her eyes in all four positions of gaze for a period of 3 minutes to induce a redistribution of subarachnoid fluid. The ultrasound probe was then placed on the temporal bulbar conjunctiva with the eye in the primary position. On the echographic screen a transverse B-scan of the orbital optic nerve could be seen (Fig 2A), and confirmed by visu-
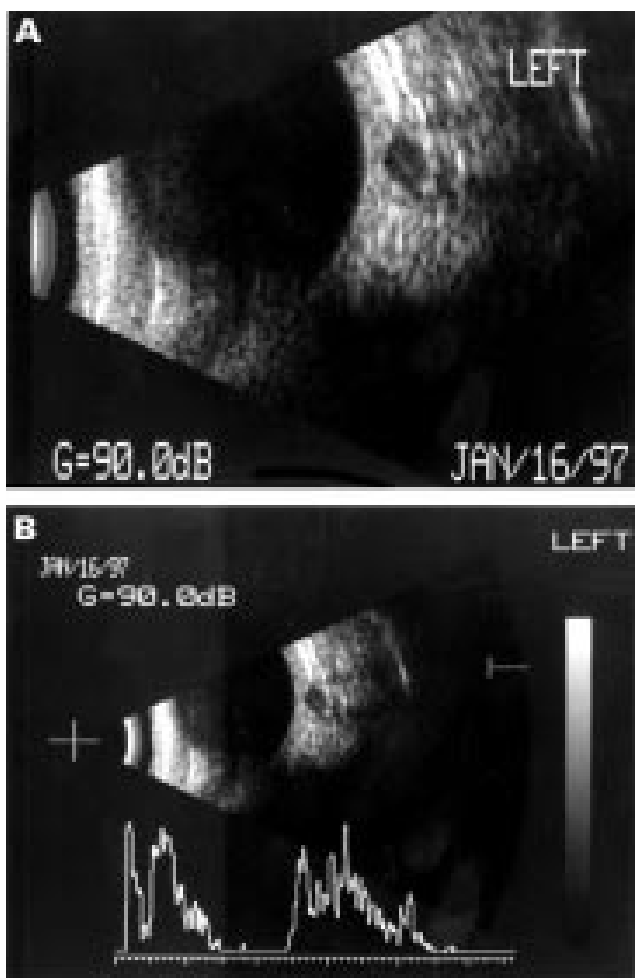

Figure 2 (A) Cross sectional B-scan echograph of the retrobulbar optic nerve. The interpial space appears dark and the dural sheath can be clearly seen. (B) Superimposed $A$-scan confirms the scan through the nerve is

perpendicular, as the distal dural echo is within $20 \%$ of the height of the proximal echo.

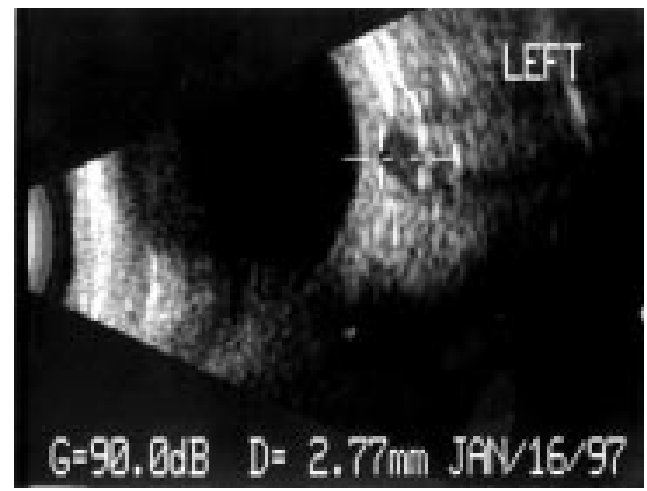

Figure 3 The interpial diameter is calculated by the instrument as the distance between two cursors placed on the dural sheath by the operator.

alisation of the dural echoes on a superimposed A-scan (Fig 2B). Optic nerve diameter was calculated as the maximal interpial distance in the horizontal plane (Fig 3). The perimeter of the optic nerve was then delineated with the aid of a cursor, and the area within this was calculated by the instrument as the optic nerve cross sectional area (Fig 4).

Previous investigators have found the orbital optic nerve to be of uniform thickness throughout its course. ${ }^{5}$ Nevertheless, in order to minimise intersubject variability, we took all optic nerve measurements $2-4 \mathrm{~mm}$ posterior to the globe. Each measurement was the mean of five readings taken by one experienced ultrasonographer (PAG) in a masked fashion. The readings were repeated on a separate occasion, with an interval of at least 1 hour between measurements, in order to calculate test-retest variability. Echographic optic nerve diameter (OND) estimates were made in one randomly selected eye of all 156 volunteers. Measurements of optic nerve cross sectional area were taken in one eye of all glaucoma and OHT subjects, and in 21 controls. Finally, in order to investigate interocular symmetry of optic nerve dimensions, OND was measured in both eyes of 70 control and 21 glaucoma subjects. However, because non-independence of fellow eyes might bias the results, only readings of the first (randomly selected) measured optic nerve were used for comparisons between subject groups in terms of absolute OND and optic nerve cross sectional area (ONCSA) values.

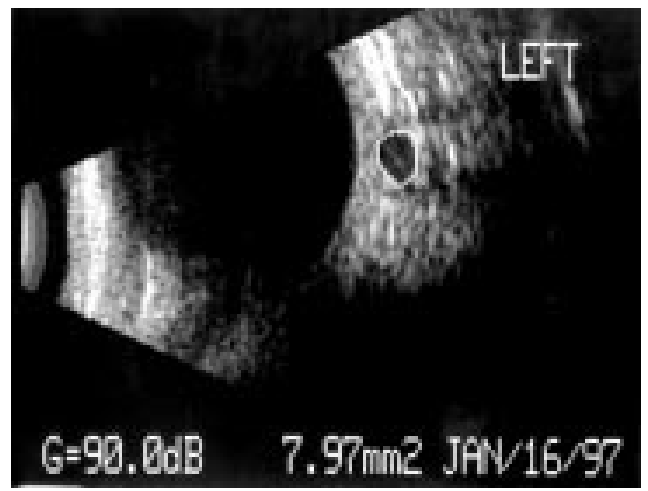

Figure 4 The optic nerve cross sectional area is calculated by the instrument as the area enclosed by the dural sheath, which is marked with a cursor by the operator. 
Table 1 Demographic data for all study subjects

\begin{tabular}{lllll}
\hline & Control group $(n=90)$ & Glaucoma group $(n=49)$ & OHT group $(n=17)$ & $p$ Value \\
\hline $\begin{array}{l}\text { Age (years): } \\
\text { mean (SD) }\end{array}$ & $64.8(11.7)$ & $69.05(11.4)$ & $61.9(7.2)$ & Control/G1: 0.2 \\
range & $46.2-81.9$ & $33.5-84.1$ & $52.8-75.1$ & $\begin{array}{l}\text { Control/OHT: } 0.39 \\
\text { OHT/G1: } 0.02\end{array}$ \\
$\begin{array}{l}\text { Sex: } \\
\text { male }\end{array}$ & 52 & & & $\chi^{2}=0.285$ \\
$\quad$ female & 38 & 29 & 11 & $\mathrm{p}=0.8672$ \\
$\begin{array}{l}\text { Race: } \\
\quad \text { White }\end{array}$ & 69 & 20 & 6 & $\chi^{2}=0.983$ \\
$\quad$ Asian & 21 & 90 & 12 & $\mathrm{p}=0.6117$ \\
\hline
\end{tabular}

OHT = ocular hypertension; $\mathrm{Gl}=$ glaucoma.

Table 2 Retrobulbar optic nerve dimensions for control, glaucoma, and ocular hypertensive eyes

\begin{tabular}{|c|c|c|c|c|}
\hline Optic nerve measurement & $\begin{array}{l}\text { Control group } \\
(n=90)\end{array}$ & Glaucoma group $(n=49)$ & $\begin{array}{l}\text { OHT group } \\
(n=17)\end{array}$ & $p$ Value \\
\hline $\begin{array}{l}\text { Diameter }(\mathrm{mm}): \\
\text { mean }(\mathrm{SD}) \\
\text { range }\end{array}$ & $\begin{array}{l}2.98(0.36) \\
2.21-3.92\end{array}$ & $\begin{array}{l}2.58(0.50) \\
1.62-3.74\end{array}$ & $\begin{array}{l}3.02(0.36) \\
1.8-3.84\end{array}$ & $\begin{array}{l}\text { Control/Gl: }<0.0001 \\
\text { Control/OHT: }=0.66 \\
\text { OHT/G1: }=0.01\end{array}$ \\
\hline $\begin{array}{l}\text { Cross sectional area }\left(\mathrm{mm}^{2}\right) \text { : } \\
\text { mean }(\mathrm{SD}) \\
\text { range }\end{array}$ & $\begin{array}{l}(\mathrm{n}=21) \\
8.25(1.67) \\
5.7-11.2\end{array}$ & $\begin{array}{l}(\mathrm{n}=49) \\
6.68(2.58) \\
2.87-13.43\end{array}$ & $\begin{array}{l}(\mathrm{n}=17) \\
8.86(2.08) \\
4.9-12.5\end{array}$ & $\begin{array}{l}\mathrm{p} \text { Value } \\
\text { Control/Gl: }=0.004 \\
\text { Control/OHT }=0.57 \\
\text { OHT/Gl: }=0.006\end{array}$ \\
\hline
\end{tabular}

$\mathrm{OHT}=$ ocular hypertension; $\mathrm{Gl}=$ glaucoma .

Statistical methods used to investigate factors that might influence optic nerve dimensions included multiple regression analysis and ANOVA for numerical and categorical data respectively. Reproducibility of our five consecutive readings was expressed in terms of the coefficient of repeatability. This represents the value below which the difference between two measurements will lie with probability 0.95 and is given by:

coefficient of repeatability $=2 \sqrt{2 \times \mathrm{SD}^{2}}$

Test-retest variability was estimated by calculating the $95 \%$ limits of agreement between initial and retest values. Statistical comparisons between the subject groups in terms of optic nerve measurements were made using the non-parametric Mann-Whitney U test. Interocular symmetry of OND was estimated by calculating the difference in the measurements between fellow eyes. Using the $F$ test, the variance of these differences was then compared for different subject groups.

\section{Results}

The control group (90 volunteers) and the glaucoma group (49 volunteers) were statistically similar in terms of age, sex, and race, but ocular hypertensive subjects were significantly younger than glaucoma subjects (Table 1). In the control subjects, the mean spherical equivalent was +0.12 (SD 2.06) dioptres and the mean axial length was $22.86(1.416) \mathrm{mm}$. Height ranged from 130.2 to $200.3 \mathrm{~cm}$, with a mean of $165.69 \mathrm{~cm}$.

In healthy volunteers the echographic measurements of the interpial diameter of the optic nerve ranged from 2.21 to $3.92 \mathrm{~mm}$, with a mean of 2.98 (SD 0.36) $\mathrm{mm}$. The measurements were independent of height (multiple regression analysis: $p=0.21$ ), axial length $(p=0.74)$, spherical equivalent $(p=0.97)$, sex (ANOVA: $p=0.36)$, or race $(p=0.14)$. The mean (SD) optic nerve cross sectional area was $8.25(1.67) \mathrm{mm}^{2}$ (range 5.7 to $11.2 \mathrm{~mm}^{2}$ )
Reproducibility of OND readings in control subjects was $0.149 \mathrm{~mm}$ (coefficient of repeatability). Test-retest variability of interpial diameter, given by the $95 \%$ limits of agreement between initial and retest values, was -0.02 (0.29) $\mathrm{mm}$.

In glaucoma subjects, the mean (SD) optic nerve diameter and cross sectional area was $2.58(0.50) \mathrm{mm}$ and $6.68(2.58) \mathrm{mm}^{2}$ respectively. These measurements were significantly smaller than for control eyes (Table 2).

The mean (SD) OND and ONCSA for ocular hypertensive eyes was $3.02(0.36) \mathrm{mm}$ and $8.86(2.08) \mathrm{mm}^{2}$ respectively. These readings were statistically comparable to those of control subjects, but significantly greater than glaucoma eyes (Table 2).

In 70 control and 21 glaucoma subjects we measured and compared the OND of fellow eyes. The mean (SD) difference between the diameter of paired optic nerves was -0.008 (0.17) $\mathrm{mm}$ (range -0.45 to $+0.4 \mathrm{~mm}$ ) and $-0.088(0.53) \mathrm{mm}$ (range -1.54 to $+0.84 \mathrm{~mm}$ ) for control and glaucomatous eyes respectively $(\mathrm{F}=0.107 ; \mathrm{p}<0.0001)$.

\section{Discussion}

Several investigators have demonstrated retinal nerve fibre layer loss in glaucomatous eyes, ${ }^{67}$ and a recent histomorphometric study has shown that the number of optic nerve fibres is significantly and linearly correlated with optic nerve thickness in normal and glaucoma subjects. ${ }^{8}$ We postulated, therefore, that the diameter and cross sectional area of the orbital optic nerve would be reduced in eyes suffering from glaucoma. We tested this hypothesis by comparing orbital optic nerve measurements of normal, glaucomatous and ocular hypertensive eyes. We also calculated the reproducibility and test-retest variability of our technique, and investigated the effect of several ocular and non-ocular variables on optic nerve dimensions. 
Our measurements of optic nerve diameter in normal subjects were comparable with those of previous investigators. ${ }^{9}{ }^{10}$ The technique we employed was highly reproducible and not subject to clinically meaningful test-retest variability.

We found orbital optic nerve diameter to be inversely related to the age of the subject. This finding is consistent with histological studies reporting an age related decrease in axonal count of the human optic nerve. ${ }^{11}$ Our measurements were independent of sex, race, axial length, refractive error, or subject height.

We have shown that mean OND and ONCSA were significantly smaller in glaucoma subjects than in age matched controls. This result is consistent with the findings of Dichtl and Jonas. ${ }^{10}$ In their study mean optic nerve thickness was also found to be reduced in glaucomatous eyes, and to decrease significantly with decreasing neuroretinal rim area. However, in contrast with our results they reported optic nerve measurements to be independent of age. The discrepancy between the studies in this respect may reflect the relatively small size of their sample (16 control and 31 glaucoma subjects).

In the present study no statistically significant difference in optic nerve dimensions was noted between eyes with ocular hypertension and age matched normal eyes. This finding is not in accordance with previous reports of optic disc changes associated with OHT, as demonstrated by Heidelberg retinal tomography and morphometric analysis of stereoscopic photographs. ${ }^{12}{ }^{13}$ It may be that optic nerve changes in ocular hypertension are too subtle for detection by ultrasonography of the retrobulbar optic nerve.

Nevertheless, it is worth noting that optic nerve dimensions were significantly smaller in glaucomatous eyes than in ocular hypertensive eyes. However, having shown that optic nerve diameter is inversely related to age, a conclusion regarding the relative optic nerve measurements in glaucoma and ocular hypertension cannot be drawn from these data because of the significantly younger age of OHT subjects.

There was greater interocular asymmetry of orbital optic nerve diameter in glaucomatous subjects than in age matched controls. We believe this finding may reflect the difference in optic disc cupping between fellow eyes that is associated with glaucoma, ${ }^{14}$ although we did not correlate our optic nerve measurements with optic disc topography.

There is much controversy regarding the pathogenesis of glaucomatous optic cupping. Some investigators believe the optic atrophy to be the result of a disturbance of the vascular flow to the optic nerve, ${ }^{15}$ while others believe it occurs in response to the mechanical effect of raised IOP on axon bundles. ${ }^{16}$ The debate regarding the mechanism of optic nerve fibre loss in glaucoma is likely to continue. However, loss of optic nerve axons has been demonstrated histologically in glaucoma ${ }^{8}$ and optic nerve dimensions, as measured by magnetic resonance imaging quantitative analysis, have been shown to be significantly reduced in optic atrophy. ${ }^{17}$

The diagnosis of glaucoma is made in the presence of a characteristic form of optic neuropathy and visual field defect, with some regard to the level of intraocular pressure. ${ }^{18}$ However, optic disc morphometry may be difficult to evaluate in the presence of small or tilted discs, ${ }^{19}$ or impossible to visualise if media opacities exist. The role of static perimetry in establishing a diagnosis may also be restricted by the physical or mental limitations of the patient. The results of this study indicate that echographic measurements of the orbital optic nerve may assist the clinician in the assessment of the glaucoma suspect. Optic nerve dimensions below the lower limit of the $95 \%$ interval for normal individuals (OND <2.25 mm; ONCSA $<4.89 \mathrm{~mm}^{2}$ ) should be considered pathologically reduced. Small orbital optic nerves can be added to the traditional triad of raised IOP, arcuate field defects, and optic disc changes that suggest a diagnosis of glaucoma.

In conclusion, we have shown that echographic measurements of orbital optic nerve are reproducible and not subject to clinically meaningful test-retest variability. Optic nerve diameter decreases with increasing age but is unrelated to axial length, spherical equivalent, sex, race or subject height. Glaucoma is associated with reduced retrobulbar optic nerve diameter and cross sectional area, and greater interocular asymmetry of orbital optic nerve dimensions. Ultrasonographic measurements of the orbital optic nerve have a significant role to play in the assessment of the glaucoma suspect.

1 Atta HR. Imaging of the optic nerve with standardised echography. Eye 1988;2:358-66.

2 Jonas JB, Gusek GC, Naumann GOH. Optic disk morphometry in high myopia. Graefes Arch Clin Exp Ophthalmol 1988;226:587-90.

3 Ossoenig KC, Cennamo G, Byrne SF. Echographic differential diagnosis of optic nerve lesions. Doc Ophthalmol Proc Ser 1981;29:327-31.

4 Byrne SF. Evaluation of the optic nerve with standardised echography. In: Smith JL, ed. Neuro ophthalmology now 1986:45-66.

5 Ossoinig KC, Cennamo U, Frazier Byrne S. Standardized echography of the optic nerve. In: Till P, ed. Ophthalmic echography. Vol 13. Chapter 1. Dordrecht, Netherlands: Kluwer Academic Publishers, 1993:3-99.

6 Autzen T, Pugesgaard T, Work K. Automated static perimetry and nerve fibre layer defects in glaucoma and controls. Acta Ophthalmol (Copenh) 1990;68:677-80.

7 Airaksinen PJ, Drance SM, Douglas GR, Schulzer M, Wijsman K. Visual field and retinal fiber layer comparisons in glaucoma. Arch Ophthalmol 1985;103:205-7.

8 Jonas JB, Schmidt A, Muller-Bergh JA, Naumann GOH. Optic nerve fiber count and diameter of the retrobulbar optic nerve in normal and glaucomatous eyes. Graefes Arch Clin Exp Ophthalmol 1995;233:421-4.

9 Dees C, Buimer R, Dick AD, Atta HR. Ultrasonographic Dees C, Buimer R, Dick AD, Atta HR. Ultrasonogra
investigations of optic neuritis. Eye 1995;9:488-94.

10 Dichtl A, Jonas JB. Echographic measurement of optic nerve thickness correlated with neuroretinal rim area and visual field defect in glaucoma. Am f Ophthalmol 1996;122:5149.

11 Balazi AG, Rootman J, Drance SM, Douglas GR. The effect of age on the nerve fiber population of the human optic nerve. Am $\mathcal{f}$ Ophthalmol 1984;97:760.

12 Zangwill LM, Van Horn S, De Souza Lima M, Sample PA, Weinreb RN. Optic nerve head topography in ocular hypertensive eyes using confocal scanning laser ophthalmoscopy. Am ₹ Ophthalmol 1996;122:520-5.

13 Jonas JB, Konigsreuther KA. Optic disk appearances in ocular hypertensive eyes. Am f Ophthalmol 1994;117:732-40.

4 Scimeca HA. Optic disc changes in glaucoma. Int Ophthalmol Clin 1979;19:127-54.

15 Schulzer M, Drance SM, Carter CJ, et al. Biostatistical evidence for two distinct chronic open angle glaucoma populations. Br f Ophthalmol 1990;74:196-200. 
16 Gaasterland D, Tanishima T, Kuwabara T. Axoplasmic flow during chronic experimental glaucoma. I Light and electrom microscopic studies of the monkey optic nerve head during development of glaucomatous cupping. Invest Ophthalmol Vis Sci 1978;17:838-46.

17 Parravano JG, Toledo A, Kucharzyk W. Dimensions of the optic nerves, chiasm, and tracts: MR quantitative compari- sons between patients with optic atrophy and normals. Fournal of Computer Assisted Tomography 1993;17:688-90.
Sommer A. Doyne lecture: Glaucoma: facts and figures. Eye Sommer A. Doyne

19 Jonas JB, Fernandez MC, Naumann GOH. Glaucomatous optic nerve atrophy in small discs with low cup-to-disc ratios. Ophthalmology 1990;97:1211-5. 